\title{
Challenges of Energy Security to the Industrialisation and Sustainable Development in Vietnam
}

\author{
Nguyen Tan Phat \\ University of Economics \& Law, Vietnam National University HCMC, Ho Chi Minh City, Vietnam \\ Email:ngtaphat@yahoo.com
}

Received June 19, 2012; revised July 20, 2012; accepted July 27, 2012

\begin{abstract}
Vietnam, during the industrialisation, has been facing the problem of energy security, the manifestation of which is lack of electricity on a large scale, affecting the growth of production and people's lives. In the past years, the fact that energy development has depended mainly on hydroelectricity and thermo-electricity but taken little care of clean energy has been opening up problems related to environment and sustainable development. Thus, at the same time, Energy Branch has to tackle 2 issues. The first is meeting the demand of energy for industrialization and social-economic growth. The second is developing sustainable energy, particularly safe and renewable power.
\end{abstract}

Keywords: Energy; Energy Security; Energy Policy; Energy Structure; Energy Strategy

\section{Energy, Energy Policy and Energy Development}

In the past, the term of Energy was approached and explained in the relation of physics. Not until has the energy branch become an important factor in the strategy of industrialization and the foundation of economic growth. Energy category has been asymptotic and acknowledged in the social-economic angle.

According to Webster's New Word College Dictionary, energy resources include petroleum, coal, gas, wind, nuclear fuel, and sunlight, from which energy in the form of electricity, heat, etc. can be produced [1].

According to the Encyclopedia, Energy is the capacity for doing work. In physics, "work" has a more formal definition than in everyday life: it means the ability to exert a force through a distance. If you pick up this book, energy stored in molecular bonds inside your body is released to move the book's mass. The energy was stored in the molecules of the foods you ate and is released through a chemical reaction. Food provides the fuel that gives us energy [2].

According to Britannica encyclopedia, Energy, in physics, the capacity for doing work. It may exist in potential, kinetic, thermal, electrical, chemical, nuclear, or other various forms. There are, moreover, heat and work-i.e., energy in the process of transfer from one body to another. After it has been transferred, energy is always designated according to its nature. Hence, heat transferred may become thermal energy, while work done may manifest itself in the form of mechanical energy [3].
Energy has become increasingly vital to the foundations of industrial manufacture and civilized life of humans in the modern world. While the demand of using energy has been greater and greater, natural resources are not never-lasting, particularly coal and petroleum energy that has been being used up day by day. Besides, energy is both an important branch of the economy and one of the branches having a great effect on the environment, causing toxic waste due to the exploitative activity and using different forms of energy, especially fossil fuels. Hence, seeking more abundant and more sustainable energy sources is a mission of humankind and is also an opportunity for those who become owners of new energy resources.

Thus, the demand of energy has been on the rise and become scarce, forcing all nations to make suitable policy of energy development. The attribute of Energy is expanded into energy policy.

Energy policy is the manner in which a given entity (often governmental) has decided to address issues of energy development including energy production, distribution and consumption. The attributes of energy policy may include legislation, international treaties, incentives to investment, guidelines for energy conservation, taxation and other public policy techniques [4].

Another explanation, Energy policy is a plan of action for tackling issues related to energy supply, demand, development of energy related industry and trade and consequences of energy activities.

Energy development is the effort to provide sufficient primary energy sources and secondary energy forms for 
supply, cost, impact on air pollution and water pollution, mitigation of climate change with renewable energy [5].

Energy development is the field concerned with providing abundant and accessible energy to all humans. It is the progressive development of knowledge, skills and institutions for capturing ever more copious and diverse primary energy sources and converting them to ever more convenient secondary energy forms, such as electrical energy and cleaner fuels. In all steps both quantitative aspects, harnessing more energy, and qualitative aspects, more efficient use, are important [6].

\section{Energy Development in General in Vietnam}

Kinds of energy to generate electricity. Systems of energy to produce electricity in Vietnam in the past years has been rather diverse including a wide variety of forms based on its natural advantages, among which are the 3 main sources such as hydroelectricity, coal thermo-elec- tricity and gas thermo-electricity. Figure 1 to show that in 2010 , hydroelectricity made up a great rate of $38 \%$ in the structure of electricity production in Vietnam, $20 \%$ of thermo-electricity and $36 \%$ of natural gas thermo-electricity. Renewable energy such as solar energy and wind energy make up a small proportion of $2 \%$, electricity is produced from the source of petroleum is $2 \%$ and the insufficient ratio of $4 \%$ is imported from China, Laos and Cambodia.

In the Southeast Asian nations, China and India, the capability of electricity production depends on the strength of fuel sources of energy production and their high technology. For example, in Singapore, energy for electricity production comes from only 2 kinds: $80.3 \%$ of natural gas and $19.7 \%$ of petroleum. In China, these sources are diverse but mainly $79.07 \%$ of coal, $16.93 \%$ of hydroelectricity and $1.98 \%$ of nuclear electricity. The energy supply in Thailand, Malaysia and Indonesia is as abundant as in Vietnam (Figure 2).

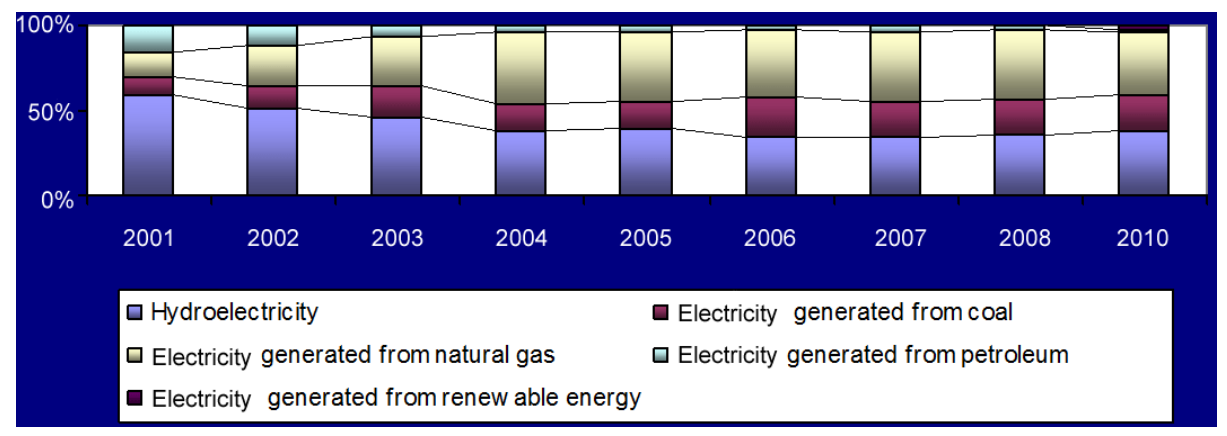

Source: figures 2001-2008 from [7]; figure 2010 calculated by the author from [8].

Figure 1. Structure of energy sources generating electricity in Vietnam in the phrase 2001-2010.

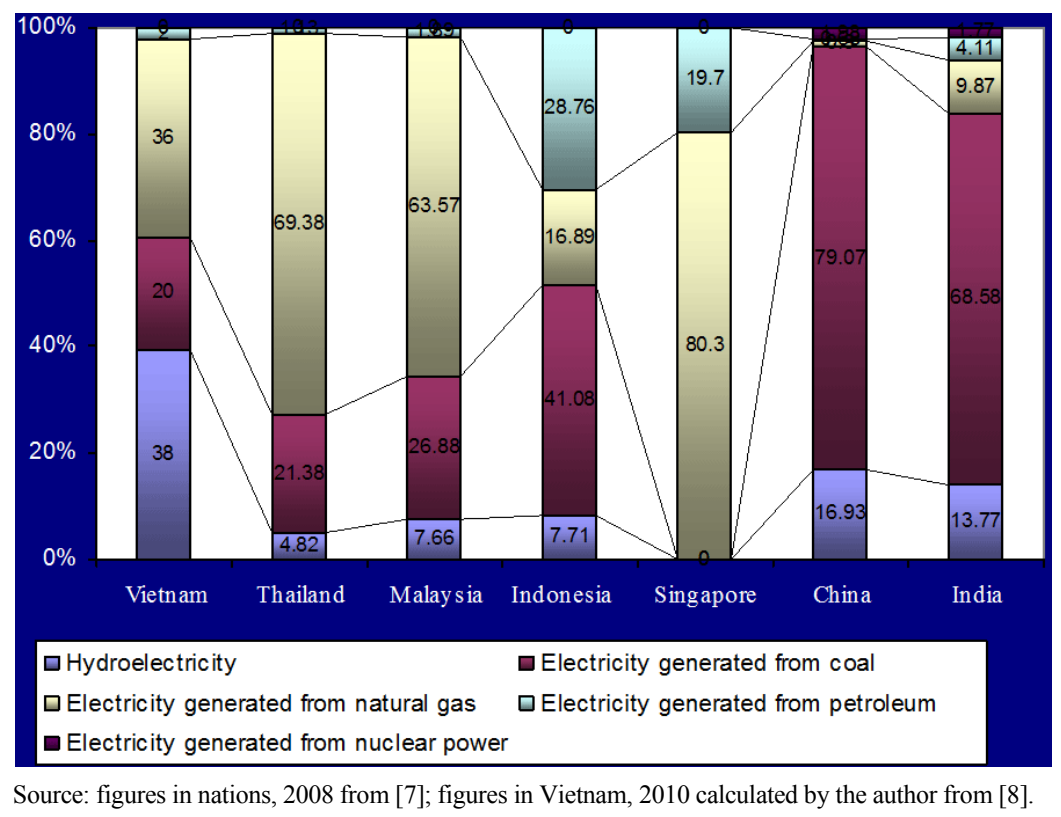

Figure 2. Structure of energy generating electricity in 2010 in Vietnam and other nations in 2008. 
The output of electricity generated and the output of electricity consumed. Table 1 shows that in the phrase 2001-2010 the output of electricity produced and consumed increased annually and electricity produced was in surplus compared with electricity consumed. This surplus rate was $12 \%$ per year in the phrase 2001-2008. However, the problem needed to make clear is the lack and import of electricity. Obviously, there has been a great loss of electricity. If the electricity surplus compared with electrical consumption is $12 \%$ and about $4 \%$ of electricity import and the power off frequently due to the insufficiency in electricity in the peak seasons, the loss of electricity is approximately $20 \%$. On the other hand, the increasing speed of electricity output produced is prone to fall the years after in comparison with the years before. In 2002, this speed increased against 2001 (16.94\%) but continually fell by $9.26 \%$ in 2008 . It indicates that the capability of electricity manufacture has been less and less developed compared with the demand of the industrialization and the social-economic growth.

The electricity produced and consumed in Vietnam is much lower than other countries like Thailand, Malaysia and Indonesia (see Table 2). It is a warning of the capacity of generating electricity for social-economic development in the coming years.

Power consumption in Vietnam has not risen high every year and the average quantity per capita is lower than Thailand, Malaysia, Indonesia, Singapore and China. In 2008, it was $799 \mathrm{kWh}$, higher than Indonesia, $591 \mathrm{kWh}$ and India, $566 \mathrm{kWh}$. In 2010, it was $984 \mathrm{kWh}$, much lower than Thailand, $2027 \mathrm{kWh}$, Malaysia $3489 \mathrm{kWh}$, Singapore $8184 \mathrm{kWh}$, and China, in 2008, $2455 \mathrm{kWh}$ (Figure 3).

Table 1. Electricity production and electricity consumption in the phrase 2001-2010.

\begin{tabular}{|c|c|c|c|c|c|c|c|c|c|c|}
\hline & Year & 2001 & 2002 & 2003 & 2004 & 2005 & 2006 & 2007 & 2008 & 2010 \\
\hline 1 & Electricity output produced & 30,608 & 35,796 & 40,925 & 46,029 & 53,462 & 60,493 & 66,857 & 73,049 & 96,000 \\
\hline 2 & Electricity output consumed & 26,365 & 30,784 & 35,653 & 41,200 & 47,593 & 54,596 & 61,970 & 68,907 & 85,590 \\
\hline 3 & Production surplus compared with consumption $(3=1-2)$ & 4243 & 5012 & 5272 & 4829 & 5869 & 5897 & 4887 & 4142 & 10,410 \\
\hline 4 & Ratio of surplus compared with consumption $(4=3 / 2)$ & $16.09 \%$ & $16.28 \%$ & $14.75 \%$ & $11.72 \%$ & $12.33 \%$ & $10.80 \%$ & $7.88 \%$ & $6.01 \%$ & $12.16 \%$ \\
\hline 5 & $\begin{array}{l}\text { Speed of electricity generation the year after compared } \\
\text { with the year before }\end{array}$ & - & $16.94 \%$ & $14.32 \%$ & $16.14 \%$ & $13.15 \%$ & $10.52 \%$ & $9.26 \%$ & - & - \\
\hline
\end{tabular}

Unit calculated: million kWh. Source: figures in 2001-2008 from [7]; figures in 2010 calculated by the author from [8].

Table 2. Electricity production \& electricity consumption in some Southeast Asian nations.

\begin{tabular}{|c|c|c|c|c|c|c|c|c|}
\hline \multirow{2}{*}{ Year } & \multicolumn{2}{|c|}{ Thailand } & \multicolumn{2}{|c|}{ Malaysia } & \multicolumn{2}{|c|}{ Indonesia } & \multicolumn{2}{|c|}{ Singapore } \\
\hline & Production & Consumption & Production & Consumption & Production & Consumption & Production & Consumption \\
\hline 2001 & 102,420 & 95,611 & 71,419 & 69,198 & 101,647 & 88,230 & 33,089 & 31,102 \\
\hline 2002 & 109,013 & 103,636 & 74,233 & 71,187 & 108,206 & 90,746 & 34,664 & 32,390 \\
\hline 2003 & 116,983 & 110,614 & 78,465 & 74,827 & 112,944 & 94,481 & 35,331 & 33,386 \\
\hline 2004 & 125,727 & 118,762 & 81,963 & 78,804 & 120,160 & 105,921 & 36,810 & 34,643 \\
\hline 2005 & 132,197 & 125,259 & 84,826 & 81,460 & 127,369 & 11,234 & 38,213 & 36,290 \\
\hline 2007 & 143,378 & 137,675 & 97,514 & 93,552 & 142,236 & 127,168 & 41,134 & 39,066 \\
\hline 2008 & 147,427 & 140,078 & 97,392 & 94,278 & 14,943 & 134,399 & 41,717 & 39,610 \\
\hline
\end{tabular}

Unit calculated: million kWh. Source: [9].

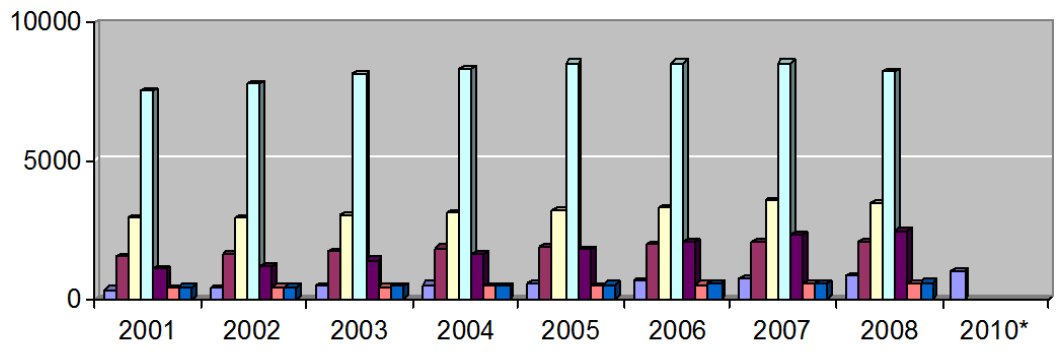

$\square$ Vietnam $\square$ Thailand $\square$ Malaysia $\square$ Singapore $\square$ China $\square$ India $\square$ Indonesia

Source: calculated by the author (figures rounded) from [10]; 2010 is the figure of per capita electric power consumption in Vietnam $(984 \mathrm{kWh})$.

Figure 3. Per capita electric power consumption in Vietnam and other countries. 
Policy strategies of energy development in Vietnam. Aware of the importance of energy in the strategy of social-economic growth, Ministry of Politics made the Resolution 18 on October, 25, 2007 about orientation of strategy of national energy development in Vietnam until 2020 with the visibility of 2050; it was also the basis of the Decision 1855, December 27, 2007 about this strategy with the specific target as followed. It is ensured that energy must be provided enough for the demand of social-economic development. It includes about 47.5 - 49.5 million TOE (ton of petroleum transferred) of primary energy sources in 2010, about 100 - 110 million TOE until 2020, about 110 - 120 triệu TOE until 2025 and will reach approximately 310 - 320 triệu TOE up to 2050 [11].

On July 21, 2011, Prime Minister approved the scheme of national energy development in the phrase 2011-2020 and considered until the year of 2030 (called shortly Electricity Scheme VII). According to the new scheme, until 2015, the electricity output produced and imported per year will have to reach $194-210$ billion $\mathrm{kWh}$ to provide enough electricity at home (the current capacity is nearly 100 billion $\mathrm{kWh}$ per year). In 2020, the first nuclear electricity plant will begin to be operated. It is the Government's requirement that up to 2020 , the total capacity of all systems should achieve about 75.000 MW compared with more than $19.000 \mathrm{MW}$ at the present.

Owing to the new structure, the dependence on hydroelectricity will fall from $35 \%$ now to $23.1 \%$ in 2020 . Renewable energy sources such as wind, sun and bioelectricity, etc. will be developed in priority from about
$3.5 \%$ in 2010 up to $4.5 \%$ in 2020 . The main source will be coal thermo-electricity, making up $46.8 \%$ of the electricity output produced and gas thermo-electricity will be $20 \%$ (Figure 4).

\section{Challenges of Energy Development}

First, the capability of electricity production will have to meet the demand of industrialization and social-econmic growth in the stage of economic restructure in the coming years, particularly the development of heavy industry and the infrastructure industry. Compared with the ability of electricity production in 2008, Vietnam generated 73 049 million $\mathrm{kWh}$, reaching $49.54 \%$ against Thailand (147 427 triệu $\mathrm{kWh}), 75 \%$ against Malaysia (97,392 triệu $\mathrm{kWh})$ and $48.88 \%$ against Indonesia (149,437 triệu kWh). In 2010, Vietnam produced 96.000 million $\mathrm{kWh}$, not as much as Malaysia in 2008 although the population is 4 times higher. While it is unable to speed up the capacity of production and reduce loss of electricity during the transmission process, the efficiency of using consumption electricity is the number 2 best solution. According to the national target until 2015 , the rate of $5 \%-8 \%$ of saving consumption electricity will be reached. This is just a side of the measure and cannot replace the number 1 best solution in which the capacity of electricity manufacture will be increased to meet the demand of national development.

Second, it is deficient in capital to meet the demand of energy development and incapable of attracting foreign and private investment. According to the estimation of

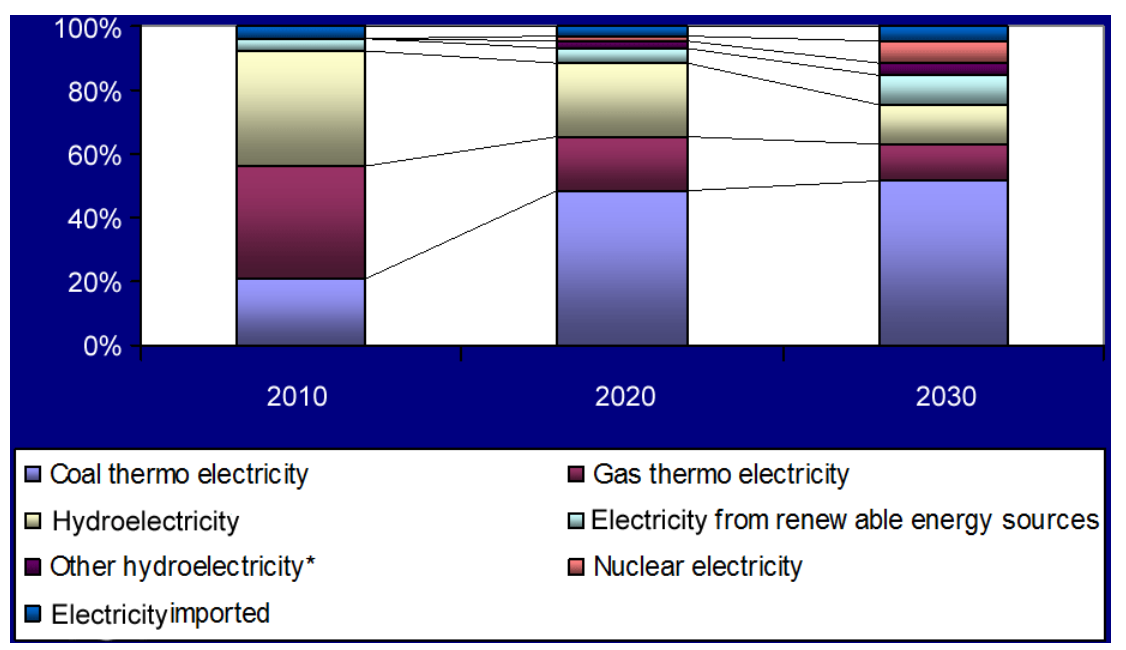

Source: calculated by the author from the following sources; Figures in 2010 collected \& classified from [8,12], Figures in 2020 and 2030 [13]. The estimation (Electricity generated from other energy sources is $2 \%$ showed in thuy dien tich nang column and $35 \%$ of gas thermo electricity is the nearly exact number predicted); ${ }^{*}$ other hydroelectricity: is hydroelectricity plant which pumps water to accumulate. It uses electrical energy from weak electricity plants taken from the system of electricity in not rush hour to have extra help in nights to pump water from low to high water tanks. When the demand of electrical energy is great, water will be let out from high to low tanks through turbine to generate electricity for electricity net.

Figure 4. Structural strategy of energy sources of electricity production in Scheme VII. 
the Ministry of Industry and Commerce in the Scheme VII, because the total investment capital of all electricity branches until 2020 will reach about 929,700 billion VND (around 48.8 billion USD, about 4.88 billion USD per year), the great source of finance must be guaranteed. It means that 5 billion USD will be needed every year during the first 10 years and 7.5 billion per year for the 10 years after that. In order to collect the capital, it is an idea of the Ministry that electricity will be sold at the market mechanism with the State's regulation. The current price is $1.242 \mathrm{VND}$ per $\mathrm{kWh}$, lower than the price with which the electricity branch can make a profit. For example, Vietnam Electricity Corporation (EVN) now is in difficulty. It made a loss of 8.185 billion VND in 2010, 3.500 billion VND in 6 months of the early 2011. Currently, it owes Vietnam petroleum Corporation (PVN) and Vietnam Corporation of coal-mineral industry (TKV) nearly 10.000 billion VND.

It is affirmed by the electricity Branch that there are numerous ways to mobilize capital for electricity but the most important thing is that electricity prices must be sufficient to compensate for costs in order for investors to invest in. The policy of electricity selling prices will be adjusted to make sure that the production cost of electricity will be approximately $8-9$ cent $/ \mathrm{kWh}$ in 2020 .

The truth is that in the past years (and even in the future) foreign investors have been afraid of investing in this field despite their interests and sufficiency in finance. It is concerned with the competitive mechanism in electricity Branch and the exclusiveness of state energy corporations. Energy Branch in general and electricity Branch in particular have been critised for their exclusiveness and privileges that have blocked the healthy development of the energy Branch. The reason why it has attracted little foreign investment through years (and in the future) is that the current mechanism has helped these energy corporations become exclusive naturally. Among the 25 electricity schemes VII until 2020, EVN has been building 14 projects; 11 projects are preparing to be invested in, 4 of them were chosen contractors to begin in 2011. Most projects are in the hand of EVN and the rest is owned by PVN, TKV and some foreign investors. The desicive role is always belonged to big stateowned corporations.

Third, finding optimal solutions in selecting forms of energy development for electricity production. For sustainable growth, renewable energy is the best choice and low-priced sources of energy are also chosen as they are fit for the capacity of state economic corporations. It is the clearly visible reality that with the ability of state corporations like EVN, PVN, TK, picking out to invest in kinds of energy that they have portions to invest in and that have low costs for per kWh such as hydroelectricity, coal thermal electricity and gas thermal electricity have been going on and will continue in the future. But renewable and safe energy sources such as wind energy and solar energy are beyond their abilities because this is the field belonging to foreign energy corporations with high-tech requirements and big rations of investment. According to the Scheme VII, renewable energy sources will make up only about $4.5 \%$ until 2020 , which is both a paradox and a reality worthwhile profound thinking as it is advantageous for Vietnam to develop wind and solar energy.

Besides, selecting nuclear energy to diversify sources of electricity provision or safety is more than everything. Vietnam is attempting to follow nuclear energy. For instance, a project of nuclear electricity in Ninh Thuan province has been deploying. It will start in 2014 and be operated in 2020. It is estimated that until 2020, nuclear electricity will make up $1.3 \%$ of all electricity. After the breakdown of Fukushima nuclear electricity plant on March, 2011, there have been diverse ideas of whether this nuclear project will be continued since it meets only $1.3 \%$ of all electricity output but the exceedingly terrible results in case of explosion. Even Germany, in which nuclear energy made up to $22.8 \%$ of electricity manufacture in 2009 and in which plants are in good conditions, has declared to stop them in 2020. Japan with $26.9 \%$ of electricity output in 2009 has begun to use it less and then will get rid of such plants to find safer renewable energy. "Public belief on nuclear safety has been shaken from the root" [14]. In the viewpoint of Vietnamese authors, it is better to use the capital for renewable energy development, especially solar and wind energy suitable for natural potentials instead of nuclear energy development.

Fourth, electricity import will definitely cause more damages than benefits related to long-term effect. In the market economy, goods import to meet the demand of consumption is condered ordinary; however, electricity merchandise has other noticeable factors. It is security in relation of environmental economy. Countries that sell electricity to Vietnam will choose best solutions for them. They will construct hydroelectricity plants by the borders or on upper reaches of rivers. The inevitable secondary consequence will be the fact that water sources on lower reaches of the Red River Delta and the Mekong Delta will run out due to the hydroelectricity projects of China and Laos ${ }^{1}$ and that flooding and environmental pollution will have a bad impact on millions of farmers. According to the author, it is vital that Vietnam manage well the transmission of electricity to avoid loss and

\footnotetext{
${ }^{1}$ In the margin of the supreme conference ASEAN 18th, Laotian Prime Minister Thoongsing Thammavong notified to stop temporarily the hydroelectricity scheme Xayaburi. This was a decision made because of the pressure of international community to protect the lower section of the Mekong River.
} 
strengthen to save electricity then it will be unnecessary to import it.

\section{What Are the Reasons of Challenges for Energy Security?}

First, management mechanism and regulations of the energy branch is unreasonable due to the natural exclusiveness of state-owned economic corporations including EVN, PVN và TKV. Among them, EVN has governed all phases including electricity production, generation, transmission, distribution, purchasing and electricity prices. Though electricity generation is no longer their exclusiveness, EVN has made up a great ratio of the overall capacity of source (about 65\%) and the other phases such as transmission and electricity distribution [15] are also in their hands. This fails to create an explicit environment for investment and has prevented from attracting capital and investment of energy corporations worldwide, especially renewable energy regarded as their strength. Each of the Vietnamese corporations has a kind of power in their hand, and the cooperation and the incoherent integration just due to their own benefits but not due to the general situation. Gas thermo-electricity belongs to PVN, coal thermo-electricity is owed by TKV and EVN possesses hydroelectricity. When electricity is sold to public, each corporation will make a profit withheld for their development. Entering in the accounts in economy related to corporations' benefits will push electricity prices higher. If there were a good integration and regulation, the prices would be lower or loss-making could be avoided and there would be capital accumulated for longterm investment.

Second, strategies made for the development of energy branch are merely within EVN' framework and neglect the consult of international energy organisations or economists as well as independent management. The economic and technological ability and human resources of EVN are limited, so are their strategies. It is showed very clearly in the Schemes VI and VII. Instead of the clearly managerial division between the Ministry of industry and trade and EVN, all strategies of energy development of this Ministry are seemingly decided mostly by EVN.

In summary, the hard mathematic problem needed to be resolved for challenges of energy development in Vietnam in short and long run is not how much the electricity prices are to make profits or not how to mobilize sufficient capital but the management mechanism of the energy branch which requires higher competitiveness, reduces loss of electricity in the phase of transmission, saves electricity effectively and makes a clear division in the State's managerial function and trade production of the Ministry of industry and trade and corporations like EVN, PVN, TKV. On the other hand, it is vital to tackle best the issue of the beneficial integration of groups of interests existing in the most 3 influential corporations: EVN, PVN và TKV so that public interests could play the key role. In addition, it is necessary to be consulted by international organisations and independent experts in energy to have smart choices in exchanging between economic factors and secure factors or between the factor of present development and sustainable growth in the future.

\section{REFERENCES}

[1] "Webster's New Word College Dictionary," Macmillan, 1995, p. 449.

[2] “Energy," 2011. http://www.Encyclopedia.com/topic/energy.aspx\#3-1G2: 3437701608-full

[3] "Study on Britannica," 2011. http://www.Britannica.com/Ebchecked/topic/187171/ener gy

[4] "Energy Policy," 2011. http://en.wikipedia.org/wiki/Energy_policy

[5] "Energy Development," 2011. http://en.wikipedia.org/wiki/Energy_development

[6] "Energy Policy-Definition," 2011. http://www.Wordiq.com/definition/energy_policy

[7] World Bank, "Electricity Power Production," 2011. http://search.worldbank.org/data?qterm=Electricityproduc tion\&language $=\mathrm{EN}$

[8] Ministry of Finance, "Provision of Electricity and Electricity Prices 2011,”2011.

http://www.mof.gov.vn/portal/page/portal/mof_vn/15397 81?pers_id=2177092\&item_id=35996444\&p_details=1

[9] World Bank, "Electricity Power Production \& Electricity Power Consumption," 2011. http://search.worldbank.org/data?qterm=Electricityproduc tin\&language $=\mathrm{EN}$

[10] Worldbank, "Electric Power Consumption (kWh per Capita)," 2011.

http://search.worldbank.org/data?qterm=Electricity+per+ capita\&language $=\&$ format $=$

[11] Prime Minister and Government, "Approval of Strategy of National Energy Development in Vietnam until 2020, with the Visibility of 2050," Decision Number 1855, 2007.

[12] Ministry of Industry \& Trade, 2011. http://www.moit.gov.vn/web/guest/tintuc?p_p_id=cmsvie wportlet_WAR_vsi_portlets_INSTANCE_XbBg\&p_p_a 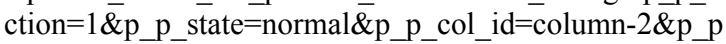 ccol_pos $=2 \& p$ p_p_col_count $=3 \&$ _cmsviewportlet WAR vsi_portlets_INSTANCE_XbBg_catId $=12 \&$ _cmsviewpor tlet_WAR_vsi_portlets_INSTANCE_XbBg_curPg $=0$ \&_ cmsviewportlet_WAR_vsi_portlets_inSTANCE_XbBg $\operatorname{arcId}=6968$

[13] Prime Minister and Government, "Approval of the Scheme of National Electric Development in the Phrase 20112020, Considered until 2030," Decision Number 1208, 2011.

[14] Y. Amano, “General Manager of International Atomic 
Energy Agency (IAEA) Made at the Opening of Ministry Conference of Nuclear Safety," Vienna, 20 June 2011.

[15] "Problems of Restructuring Electricity Branch," 2011. http://daukhi.vietnamnet.vn/vn/tin-moi/1428/nhung-van-d e-dat-ra-trong-tai-co-cau-nganh-dien.html 